CZASOPISMO INŻYNIERII LA¿OWEJ, ŚRODOWISKA I ARCHITEKTURY JOURNAL OF CIVIL ENGINEERING, ENVIRONMENT AND ARCHITECTURE

JCEEA, t. XXXIV, z. 64 (4///17), październik-grudzień 2017, s. 161-168, DOI:10.7862/rb.2017.202

\author{
Krzysztof JABLOŃSKI ${ }^{1}$ \\ Włodzimierz STEMPSKI ${ }^{2}$
}

\title{
ROLA LASÓW I LEŚNICTWA W POCHLANIANIU GAZÓW CIEPLARNIANYCH
}

Wśród działań zmierzających do złagodzenia zmian klimatycznych ważną rolę odgrywają lasy oraz aktywnie prowadzona gospodarka leśna. Lasy pełnią rolę nie tylko pochłaniacza dwutlenku węgla, ale stanowią ważne źródło surowca drzewnego i biomasy leśnej, dostarczając substytutów materiałów niedrzewnych oraz paliw kopalnych. Obecnie, informacje o działaniach w zakresie zalesień, wylesień oraz gospodarki leśnej stanowią część corocznych raportów, przygotowywanych na mocy ramowej konwencji klimatycznej oraz protokołu z Kioto. Wśród sektorów objętych sprawozdawczością tylko kategoria „Użytkowanie gruntów, zmiany użytkowania gruntów i leśnictwo" (LULUCF) stanowi pochłaniacz emisji gazów cieplarnianych netto. W Polsce w sektorze LULUCF lasy cechują się największym pochłanianiem dwutlenku węgla w przeliczeniu na jednostkę powierzchni, osiągając wartość 4,42 t $\mathrm{CO}_{2}$ na ha. Gospodarka leśna przyczynia się do pochłaniania dwutlenku węgla znacznie bardziej niż zalesianie netto. Średnio, w ostatnich latach wielkość pochłaniania dwutlenku węgla $\mathrm{z}$ tytułu prowadzenia gospodarki leśnej w Polsce wynosiła blisko $38 \mathrm{mln}$ ton rocznie, zaś zalesiania netto rocznie pochłaniały średnio nieco ponad $2 \mathrm{mln}$ ton dwutlenku węgla. Obliczenia wskazują, że wprowadzenie jednostek pochłaniania dwutlenku węgla $\mathrm{z}$ tytułu prowadzenia gospodarki leśnej i zalesień do handlu emisjami, przy obecnych cenach dwutlenku węgla, mogłoby być źródłem przychodu na poziomie ok. $70 \mathrm{mln}$ Euro rocznie. Nie tylko sam fakt istnienia lasów jako ekosystemu, ale aktywne prowadzenie gospodarki leśnej przyczynia się do sekwestracji dwutlenku węgla, co stawia leśnictwo w roli ważnego czynnika przeciwdziałającego zmianom klimatycznym i wzywa do rychłego włączenia sektora LULUCF do celu redukcyjnego emisji.

Słowa kluczowe: gospodarka leśna, sekwestracja węgla, pochłaniacz $\mathrm{CO}_{2}$, substytucja

\section{Wprowadzenie}

Problematyka związana z ochroną klimatu od kilkudziesięciu lat stanowi przedmiot zainteresowania społeczności naukowej i polityków. Jest to obecnie

\footnotetext{
${ }^{1}$ Autor do korespondencji / corresponding author: Krzysztof Jabłoński, Uniwersytet Przyrodniczy w Poznaniu, Katedra Techniki Leśnej, ul. Wojska Polskiego 71C, 60-625 Poznań; tel. 618487640; jabkrys@up.poznan.pl

${ }^{2}$ Włodzimierz Stempski, Uniwersytet Przyrodniczy w Poznaniu, Katedra Techniki Leśnej, ul. Wojska Polskiego 71C, 60-625 Poznań; tel. 618487644; stempski@up.poznan.pl
} 
jedno z największych wyzwań, w obliczu którego stoi współczesny świat. Wyróżnia się kilka długoterminowych trendów [1], dotykających, mniej lub bardziej bezpośrednio, działań podejmowanych w zakresie gospodarowania przyrodą. Są to: wzrastająca liczba ludności na świecie, zmiany klimatyczne, oraz rosnący niepokój o zaopatrzenie w nośniki energii.

Kolejne raporty Międzyrządowego Panelu ds. Zmian Klimatu (IPCC) potwierdzają istotny wpływ czynników antropogenicznych na zmieniający się klimat. Konwencja klimatyczna, a następnie, obowiązujący od 2005 r., Protokół z Kioto stanowiły wyraz działań politycznych, zmierzających do ograniczenia negatywnego wpływu człowieka na ziemski klimat. Problematyka ochrony środowiska naturalnego znalazła swój wyraz także w dokumentach opracowanych przez autorytety moralne, jak chociażby Encyklika Laudato Si, Papieża Franciszka [2].

Lasy na świecie stanowią istotny zbiornik węgla, zawierają bowiem ponad $80 \%$ węgla zmagazynowanego w roślinach lądowych i około $70 \%$ węgla zmagazynowanego $\mathrm{w}$ glebach [3]. Na terenie Europy lasy zajmują powierzchnię $159 \mathrm{mln}$ ha, co odpowiada $37 \%$ powierzchni kontynentu. Średnio pozyskuje się $75 \%$ przyrostu surowca na pniu, co prowadzi do średniorocznej akumulacji węgla na poziomie $435 \mathrm{Mt} \mathrm{CO}_{2}$ [4]. W Polsce, w najpowszechniej występujących borach sosnowych, ogólna pula węgla $\mathrm{w}$ ekosystemie wynosi $148 \mathrm{t} / \mathrm{ha}$ [5], z czego $91 \mathrm{t}$ przypada na fitomasę a $57 \mathrm{t}$ na węgiel zgromadzony w glebie. Ocena bilansu węgla wskazuje, że w ciągu roku 1,3 t C/ha jest wiązane przez ekosystem w dendromasie i glebie mineralnej, co stanowi 13\% produkcji pierwotnej brutto [5]. Oznacza to, że zdecydowana większość dwutlenku węgla pobieranego przez las z atmosfery jest do niej zwracana w trakcie procesów oddychania. W naturalnych lasach tropikalnych wartości te są znacznie większe i sięgają $150-250 \mathrm{t} / \mathrm{ha}[6]$.

Lasy stanowią one nie tylko zbiorniki węgla wbudowanego w biomasę czy pochłaniacze $\mathrm{CO}_{2}$, ale są także źródłem różnorodnych surowców oraz stanowią odnawialne źródło energii. Lasy wpływają na bilans gazów cieplarnianych w dwojaki sposób. Przede wszystkim pochłaniają dwutlenek węgla z atmosfery, wbudowując go w biomasę. Stanowią więc pochłaniacz węgla, którego cześć jest dalej transferowana do gleby w toku obumierania biomasy żywej, zaś część pozostaje zmagazynowana $\mathrm{w}$ wyrobach powstałych $\mathrm{z}$ pozyskanego drewna, część zaś wraca do atmosfery w procesie respiracji. Drugą ważną rolą spełnianą przez lasy jest substytucja paliw kopalnych (w przypadku wykorzystywania biomasy leśnej do celów energetycznych) oraz materiałów (budowlanych, izolacyjnych, opakowań, itp.). Potencjał mitygacyjny lasów oparty jest o naturalny obieg węgla w przyrodzie oraz mechanizm substytucyjny.

Badania naukowe [7] wskazują, że w dłuższym okresie efekty wynikające z substytucji materiałów niedrzewnych przez produkty drzewne oraz paliw kopalnych przez paliwa drzewne mają większe znaczenie niż efekty zmian zawartości węgla w „zbiorniku $\mathrm{CO}_{2}$ ” jakim jest las. 


\section{Umocowanie leśnictwa w dokumentach politycznych}

Ramowa Konwencja narodów Zjednoczonych w Sprawie Zmian Klimatu (Konwencja Klimatyczna)[8] w artykule 4, nie tylko zobowiązuje do redukcji i ograniczania antropogenicznych emisji gazów cieplarnianych m.in. w leśnictwie (art. 4, pkt. 1c), ale także do podniesienia efektywności pochłaniaczy gazów cieplarnianych, uwzględniając w tym lasy (art. 4, pkt. 1d). O istotnej roli lasów i leśnictwa świadczy tekst Protokołu z Kioto[9], a w szczególności jego artykuły 3.3 i 3.4. Artykuł 3.3 Protokołu mówi o możliwości włączenia działań z zakresu zalesień, ponownych zalesień i wylesień do realizacji nałożonych zobowiązań w obszarze redukcji emisji gazów cieplarnianych. Artykuł 3.4. umożliwia uwzględnienie działań związanych z prowadzoną gospodarką leśną w realizacji zobowiązań poszczególnych państw, wyszczególnionych w Aneksie I do Protokołu.

Polska nie tylko jest stroną Konwencji Klimatycznej i nie tylko ratyfikowała Protokół z Kioto, ale aktywnie dąży do zwiększenia pochłaniania gazów cieplarnianych, np. poprzez realizację polityki leśnej [10] i zwiększenie lesistości kraju do $30 \%$ w 2020 roku i $33 \%$ w połowie 21 . wieku. Polityka leśna podkreśla trwały i zrównoważony charakter gospodarki leśnej i jej wielofunkcyjność, co oznacza również realizowanie przez gospodarkę leśną funkcji ochronnych, w tym ochrony klimatu. Akumulacja węgla w biomasie i glebach wpisuje się w pierwsze z kryteriów zrównoważonej gospodarki leśnej (C1). Utrzymywanie i właściwe powiększanie zasobów leśnych ich wkładu do globalnego cyklu węglowego), które przyjęto na jednej z konferencji ministerialnych w sprawie ochrony lasów w Europie [11].

\section{Leśnictwo jako źródło emisji i pochłaniacz gazów cieplarnianych}

Na mocy zobowiązań płynących z protokołu z Kioto Polska corocznie raportuje ilości emisji i pochłaniania dwutlenku węgla, także w ramach działań z kategorii „Użytkowanie ziemi, zmian użytkowania ziemi i leśnictwo” (z ang. LULUCF). Sektor ten jest, z punktu widzenia wpływu gospodarki leśnej na bilans emisji, niezwykle istotny, bowiem w nim tkwią potencjalne możliwości leśnictwa w zakresie obniżania emisji gazów cieplarnianych netto. Sektor ten może przyczynić się do złagodzenia zmian klimatycznych nie tylko poprzez ograniczanie emisji, ale także wskutek utrzymywana i powiększania pochłaniaczy dwutlenku węgla i jego zmagazynowanych zasobów.

Raporty wykonywane dla potrzeb Ramowej Konwencji Narodów Zjednoczonych w Sprawie Zmian Klimatu (Konwencja Klimatyczna) oraz Protokołu z Kioto uwzględniają leśnictwo w kategorii „Użytkowanie gruntów, zmiany użytkowania gruntów i leśnictwo". Wśród pięciu sektorów, dla których corocznie raportowane są wielkości emisji i pochłaniania gazów cieplarnianych (ener- 
gia, procesy przemysłowe, rolnictwo, użytkowanie gruntów..., odpady i inne), sektor „Użytkowanie gruntów...”, którego najistotniejszym elementem jest leśnictwo, w roku 2013 odpowiadał za pochłanianie aż 37,6 mln ton $\mathrm{CO}_{2}$ ekw., co oznacza, że ok. 9\% emisji antropogenicznych dwutlenku węgla w Polsce zostało pochłonięte przez lasy. Leśnictwo, dominujące w kategorii „Użytkowanie gruntów, zmiany użytkowania gruntów i leśnictwo", przez pochłanianie dwutlenku węgla, ma istotny wkład w obniżenie emisyjności gospodarki i jako jedyny sektor wśród objętych sprawozdawczością, jest pochłaniaczem netto.

Jak podaje raport inwentaryzacyjny KOBiZE[12], w roku 2013, wśród kategorii użytkowania gruntów wyróżnionych w sektorze LULUCF, leśnictwo stanowiło największy pochłaniacz netto $\mathrm{CO}_{2}\left(41422 \mathrm{kt} \mathrm{CO}_{2}\right)$, a pozostałe pochłaniacze - grunty orne i pastwiska, odpowiednio 436 i 348 kt $\mathrm{CO}_{2} \mathrm{w}$ znacznie mniejszym stopniu przyczyniły się do usuwania dwutlenku węgla $\mathrm{z}$ atmosfery. Biorąc pod uwagę powierzchnie poszczególnych kategorii użytkowania gruntu, okazuje się że w przeliczeniu na jednostkę terenu pochłanianie dwutlenku węgla przez lasy jest największe, sięgając blisko 4,5 tony na ha (tab. 1).

Tabela 1. Wielkości emisji i pochłaniania dwutlenku węgla według kategorii użytkowania gruntów, na podstawie [12]

Table 1. $\mathrm{CO}_{2}$ emissions and sequestration values for different land use categories, based on [12]

\begin{tabular}{|c|c|c|c|}
\hline $\begin{array}{c}\text { Kategoria użytkowania } \\
\text { gruntu }\end{array}$ & Emisje/ pochlanianie & Powierzchnia & $\begin{array}{c}\text { Pochlanianie /emisje } \\
\text { jednostkowe }\end{array}$ \\
\cline { 2 - 4 } & tony $\mathrm{CO}_{2}$ & ha & $\mathrm{CO}_{2} /$ ha \\
\hline Lasy & -41421753 & 9369403 & $-4,42$ \\
\hline Grunty orne & -435678 & 14103689 & $-0,03$ \\
\hline Pastwiska & -348425 & 4162123 & $-0,08$ \\
\hline Tereny podmokłe & 4316309 & 1370864 & 3,15 \\
\hline Osiedla & 262232 & 2163440 & 0,12 \\
\hline
\end{tabular}

(znak ,-,, oznacza pochłanianie)

Raportowane informacje w zakresie leśnictwa obejmują działania w obszarze zalesiania, ponownego zalesiania, wylesiania oraz gospodarki leśnej. W szczególności uwzględniane są zmiany zasobów węgla w: biomasie nadziemnej, biomasie podziemnej, ściółce, martwym drewnie, glebie leśnej oraz w produktach z pozyskanego drewna. Szczegółowe zasady przygotowywania i prowadzenia rachunku dla tego sektora precyzuje decyzja 539/2013/UE [13].

W obecnym okresie rozliczeniowym emisji, obejmującym lata 2013-2020, sektor leśnictwa rozliczany jest na podstawie ilości emisji i pochłaniania, obliczanych zgodnie z metodyką IPCC [14]. Osobno rozliczeniu podlegają emisje i pochłanianie gazów cieplarnianych powstających w wyniku prowadzenia zalesień, ponownych zalesień oraz wylesień, a osobno te, które powstają w wyniku prowadzenia gospodarki leśnej. 
Zawarte w tabeli 2 dane świadczą o znacznym udziale gospodarki leśnej w całkowitej ilości pochłaniania dwutlenku węgla przez sektor leśnictwa. Zalesianie, ponowne zalesianie i wylesianie netto (art. 3.3 Protokołu z Kioto) stanowią jedynie $6 \%$ ogólnej ilości pochłoniętego dwutlenku węgla w ostatnich trzech latach sprawozdawczych. Potwierdza to szczególnie ważną rolę prowadzonej gospodarki leśnej (art. 3.4. Protokołu z Kioto) w zakresie pochłaniania gazów cieplarnianych netto. Średnio, cały sektor leśnictwa pochłania rocznie około 40 milionów ton dwutlenku węgla.

Tabela 2. Wielkości emisji i pochłaniania gazów cieplarnianych dla leśnictwa, raportowanych w ramach zobowiązań wynikających z Protokołu z Kioto, na podstawie [15]

Table 2. Emission and sequestration of GHGs for forestry, reported according to Kioto Protocol requirements, based on [15]

\begin{tabular}{|c|c|c|c|c|c|}
\hline Dzialanie & \multicolumn{2}{|c|}{ Art. 3.3. Protokolu z Kioto } & Art. 3.4 Protokołu & \multirow{2}{*}{$\begin{array}{c}\text { Razem } \\
\text { leśnictwo }\end{array}$} \\
\hline \multirow{2}{*}{ Rok } & $\begin{array}{c}\text { Zalesianie } \\
\text { i ponowne } \\
\text { zalesianie }\end{array}$ & Wylesianie & Razem & $\begin{array}{c}\text { Gospodarka } \\
\text { leśna }\end{array}$ & \\
\hline \multicolumn{7}{|c|}{ tys. ton $\mathrm{CO}_{2}$} \\
\hline $\mathbf{2 0 1 1}$ & $-2,660$ & 0,225 & $-2,435$ & $-37,359$ & $-39,794$ \\
\hline $\mathbf{2 0 1 2}$ & $-2,717$ & 0,247 & $-2,470$ & $-36,838$ & $-39,308$ \\
\hline $\mathbf{2 0 1 3}$ & $-2,291$ & 0,202 & $-2,089$ & $-39,131$ & $-41,220$ \\
\hline Średnio & $-2,556$ & 0,225 & $-2,331$ & $-37,776$ & $-40,107$ \\
\hline
\end{tabular}

Zgodnie z obowiązującą w obecnym okresie rozliczeniowym metodyką obliczania ilości emisji i pochłaniania gazów cieplarnianych powstających w wyniku prowadzenia gospodarki leśnej, coroczny bilans emisji i pochłaniania przyrównuje się do poziomu odniesienia (FMRL Forest Management Emissions Level) i dopiero powstały wynik wskazuje na ilość emisji lub pochłaniania, które można wykazać w krajowych bilansach. Poziom odniesienia został określony na 27,133 mln ton $\mathrm{CO}_{2}$. i zgłoszony przez Polskę do Sekretariatu Konwencji klimatycznej. $\mathrm{W}$ tabeli 3 przedstawiono uśrednione wartości pochłaniania $\mathrm{CO}_{2}$ w wyniku prowadzenia gospodarki leśnej, porównano je z poziomem odniesienia dla Polski oraz dodano wartości pochłaniania z zalesień/wylesień, obliczając całkowitą ilość pochłaniania $\mathrm{CO}_{2} \mathrm{ekw}$.

$Z$ racji tego, że obecnie opracowywany jest system tzw. leśnych gospodarstw węglowych [16], zmierzający do wprowadzenia pochłanianych przez leśnictwo jednostek dwutlenku węgla do obrotu handlowego obliczono potencjalne przychody z tytułu sprzedaży jednostek pochłanianego dwutlenku węgla, zakładając aktualną cenę jednej tony $\mathrm{CO}_{2}$. Przedstawiają to dwie ostatnie kolumny wspomnianej tabeli 3. Przy aktualnej cenie dwutlenku węgla oscylującej wokół poziomu 5 Euro/tonę $\mathrm{CO}_{2}$ oznaczałoby to, że można by spodziewać się przychodów na poziomie około 65-70 milionów Euro rocznie. 
Tabela 3.Potencjalne przychody z tytułu pochłaniania $\mathrm{CO}_{2}$ przez sektor leśnictwa

Table 3. Potential incomes from $\mathrm{CO}_{2}$ sequestration by the forestry sector

\begin{tabular}{|c|c|c|c|c|c|c|}
\hline $\begin{array}{l}\text { Pochlanianie } \\
\text { z gospodarki } \\
\text { leśnej }\end{array}$ & $\begin{array}{c}\text { Poziom } \\
\text { odniesienia }\end{array}$ & Nadwyżka & $\begin{array}{l}\text { Zalesienia } \\
\text { i wylesienia }\end{array}$ & $\begin{array}{l}\text { Razem } \\
\text { leśnictwo }\end{array}$ & Cena $\mathrm{CO}_{2}$ & Przychód \\
\hline \multicolumn{5}{|c|}{ tys. ton $\mathrm{CO}_{2} /$ rok } & $\mathrm{EUR} / \mathrm{t} \mathrm{CO} \mathrm{CO}_{2}$ & $\begin{array}{c}\mathrm{mln} \\
\text { EUR/rok }\end{array}$ \\
\hline 1 & 2 & $3(1-2)$ & 4 & $5(3+4)$ & 6 & $7(6 \times 5)$ \\
\hline-37776 & -27133 & -10643 & -2331 & -12975 & $5,38^{*}$ & 69,7 \\
\hline
\end{tabular}

*Cena na dzień 01.04.2016r wg [17]

\section{Podsumowanie}

Prowadzenie gospodarki leśnej, a więc głównie czynności z zakresu hodowli, ochrony i użytkowania lasu prowadzą do stałego wiązania dwutlenku węgla w ekosystemie leśnym i w produktach drzewnych substytuujących inne materiały niedrzewne, jak np. stal, beton. Prowadzenie gospodarki leśnej, m.in. poprzez optymalizację składu gatunkowego, ochronę gleby, silniejszą ochronę przed zjawiskami katastrofalnymi i zwiększenie rezerwuaru produktów z pozyskanego drewna przyczynia się do pochłaniania $\mathrm{CO}_{2} \mathrm{z}$ atmosfery znacznie bardziej niż zalesianie terenów nieleśnych. Przytoczone powyżej spostrzeżenia świadczą o tym, że zwiększanie pojemności i zdolności magazynowania dwutlenku węgla przez sektor leśnictwa nie ogranicza się jedynie do zachowania ekosystemu leśnego, ale obejmuje także aktywne gospodarowanie tym ekosystemem. Pochłanianie $\mathrm{CO}_{2}$ może, po włączeniu leśnictwa do systemu handlu emisjami, być potencjalnym źródłem istotnych korzyści materialnych, sięgających $70 \mathrm{mln}$ Euro. Działalność człowieka, która, jak się powszechnie uważa, przyczyniła się do wystąpienia niekorzystnych i niebezpiecznych $\mathrm{w}$ swoich skutkach zmian klimatycznych, może także prowadzić do ich zahamowania lub odwrócenia. Leśnictwo może być tutaj dobrym przykładem takich działań.

\section{Literatura}

[1] Lindahl K. B., Westholm E. (red.) 2015. Trender i varlden. Rapport fran Future Forests 2009-2012. Future Forests rapport serie 2015:1. Sverigeslantbruksuniversitet, Umea.

[2] Encyklika Laudato Si’ Ojca Świętego Franciszka poświęcona trosce o wspólny dom. Wyd. Diecezji Warszawsko-Praskiej. Warszawa 2015.

[3] Post W. M., Emanuel W. R., Zinke P. I., Stagenberger A. G. 1982. Soil carbon pools and world life zones. Nature, 298: 156-159.

[4] Nabuurs G-J., Delacote P., Ellison D., Hanewinkel M., Lindner M., Nesbit M., Ollikainen M., Saveresi A. 2015. A new role for forests and the forest sector in the EU post-2020 climate targets. Form science to policy 2. European Forest Institute. www.efi.int. \{data dostępu 16.03.2016 r.\}. 
[5] Zwoliński J. 1998. Obieg węgla w borach sosnowych. Prace IBL, Seria A. pp. 141-155.

[6] Koskela J., Nygren P.,Berninger F., Luukkanen O. 2000. Implications of the Kyoto Protocol or tropical forest management and land use: prospects and pitfalls. Tropical forestry reports. University of Helsinki. Helsinki.

[7] Lundmark T., Bergh J., Hofer P., Lundstrom A., Nordin A., Podel B.C., Sathre R., Taverna R., Werner F. 2014. Potential roles of Swedish forestry in the context of climate change mitigation. Forests. 5. Pp. 557-578. (www.mdpi.com/journal/forests) \{data dostępu: 31.03.2016 r.\}.

[8] Ramowa Konwencja Narodów Zjednoczonych w sprawie Zmian Klimatu. 1992. https://www.mos.gov.pl/fileadmin/user_upload/srodowisko/Ramowa_Konwencja_Nar odow_Zjednoczonych_w_sprawie_zmian_klimatu.pdf\{data dostępu: 17.03.2016 r. $\}$.

[9] Protokół z Kioto do Ramowej konwencji w sprawie zmian klimatu. 1997 (https://www.mos.gov.pl/fileadmin/user_upload/srodowisko/Protokol_z_Kioto_do_R amwej_Konwencji_Narodow_Zjednoczonych_w_sprawie_zmian_klimatu.pdf) $\{$ data dostępu: 18.03.2016 r.\}.

[10] Polityka Leśna Państwa. 1997. (https://www.mos.gov.pl/g2/big/2009_04/ /34ba398d45e363aed16d2ad3b015136a.pdf) \{data dostępu: 18.03.2016 r.\}.

[11] Aneks 1 do rezolucji L2 „Paneuropejskie Kryteria i Wskaźniki zrównoważonej gospodarki leśnej”. Trzecia Konferencja Ministrów w Sprawie Ochrony Lasów w Europie 2-4 Czerwca 1998 roku, Lizbona, 1998 (https://www.mos.gov.pl/g2/big/ /2009_04/c5fd1336a465a7f2c876dfbac9f9c8ad.pdf) \{data dostępu: 29.03.2016 r.\}.

[12] Poland's National Inventory Report2015. 2015. KOBiZE in IOŚ-PAB. Warszawa.

[13] Decyzja Parlamentu Europejskiego i Rady Nr 539/2013/UE z dnia 21 maja 2013 w sprawie zasad rozliczania emisji i pochłaniania gazów cieplarnianych w wyniku działalności związanej z użytkowaniem gruntów, zmianą użytkowania gruntów i leśnictwem oraz informacji o działaniach związanych $\mathrm{z}$ tą działalnością. Dziennik Urzędowy Unii Europejskiej L 165/80 z 18.6.2013.

[14] IPCC 2014. 2013 Revised Supplementary Methods and Good Practice Guidance Arising from the Kyoto Protocol, Hiraishi, T., Krug, T., Tanabe, K., Srivastava, N., Baasansuren, J., Fukuda, M. and Troxler, T.G. (eds)IPCC, Switzerland.

[15] National reports http://unfccc.int/national_reports/annex_i_ghg_inventories/national_ inventories_submissions/items/8812.php \{data dostępu 18.03.2016 r.\}.

[16] Drabarczyk J. 2016. Zatrzymać węgiel w lesie. Głos lasu. Nr 1, ss. 12-14.

[17] http://www.handel-emisjami.pl/ \{data dostępu: 01.04.2016 r.\}.

\section{ROLES OF FORESTS AND FOREST MANAGEMENT IN SEQUESTRATION OF GREENHOUSE GASES}

\section{S u m m a r y}

Among activities leading to climate change mitigation forests and active forest management play an important role. Forests are not only a carbon dioxide sink, but they are also a vital source of wood products and forest biomass, providing substitutes for non-wood materials and fossil fuels. Today, information about afforestation, deforestation and forest management is a part of yearly reports, submitted, according to the requirements of the climate convention and Kioto Pro- 
tocol. Among the sectors covered by the reporting, only the category Land Use, Land Use Change and Forestry (LULUCF) is a net GHG sink. In Poland in the LULUCF sector, forests are the largest carbon dioxide sink per area unit, reaching a value of $4,42 \mathrm{t} \mathrm{CO}_{2} /$ ha. Forest management contributes to the sequestration of carbon dioxide in a much larger degree than net afforestation. The average $\mathrm{CO}_{2}$ sequestration due to forest management in Poland in recent years amounted to nearly 38 mill. tons per year, while the net sequestration resulting from afforestation/deforestation activities reached over 2 mill. tons $\mathrm{CO}_{2}$. As calculations show, bringing $\mathrm{CO}_{2}$ sequestration units due to forest management into the emissions trading system could provide an income of about 70 mill. Euros per year. The existence of forests as ecosystems contributes to the sequestration of carbon dioxide, but active forest management plays an even more important role in carbon sequestration, which puts forestry into a position of a vital factor mitigating climate change and calls for a rapid inclusion of the LULUCF sector in the emissions reduction goals.

Keywords: forest management, carbon sequestration, $\mathrm{CO}_{2}$ sink, substitution

Przestano do redakcji: 7.07.2017 $r$.

Przyjęto do druku: 15.12.2017 r. 